\title{
On the relationship between battery power capacity sizing and solar variability scenarios for industrial off-grid power plants $^{*}$
}

Authors: Louis Polleux ${ }^{1,2,+}$, Thierry Schuhler ${ }^{2}$, Gilles Guerassimoff', Jean-Paul Marmorat', John Sandoval', Sami Ghazouani²

1 Center for Applied Mathematics, Mines Paristech PSL, Sophia Antipolis, France

2 Research and Development, TOTAL, Paris, France

\begin{abstract}
:
Due to its high short-term variability, solar-photovoltaic power in isolated industrial grids faces a challenge of grid reliability. Storage systems can provide grid support but come at a high cost that requires carefully evaluating power capacity needs. Battery sizing methodologies are now the focus of many studies, with a global upward trend in detailed modelling and complex optimization. However, although solar variability can be the source of uncertainties and battery oversizing, it rarely features as an input in scenarios. This study proposes several solar variability scenarios thanks to the wavelet-variability model and two variability metrics. These scenarios are employed as inputs in two sizing methodologies to compare the resulting battery capacity and draw conclusions on the role of modelling complexity and scenario identification. Results show that neglecting the photovoltaic power plant smoothing effect leads to an overestimation of the battery power support of $51 \%$. In the other hand, complex dynamic modelling may reduce the battery power capacity by $25 \%$. The economic analysis shows that a proper combination of variability scenario and battery sizing methodology may reduce the levelized costs of electricity by $3 \%$.
\end{abstract}

\section{Highlights}

- Modelling photovoltaic plant geographical smoothing avoids over-investments.

- Identifying variability scenarios is crucial to ensure continuity of supply.

- Combining ramp-detection and variability index spares the use of day-long timeseries.

\section{Keywords}

Solar variability, Storage systems, Industrial microgrid, Power quality, Wavelet variability model

\section{Nomenclature}

\begin{tabular}{|cl|}
\hline Abbreviations & Wavelet Variability Model \\
WVM & Photovoltaic \\
PV & Ramp detection algorithm \\
RDA & Local variability index \\
VI & Global Horizontal Irradiance \\
GHI & Clear sky irradiance \\
CSI &
\end{tabular}

\footnotetext{
The short version of the paper was presented at ICAE2020, Dec 1-10, 2020. This paper is a substantial extension of the short version of the conference paper.

+ Corresponding author: Louis Polleux louis.polleux@mines-paristech.fr , CMA Mines Paristech, 1 Rue Claude Daunesse, 06904 Sophia Antipolis
} 


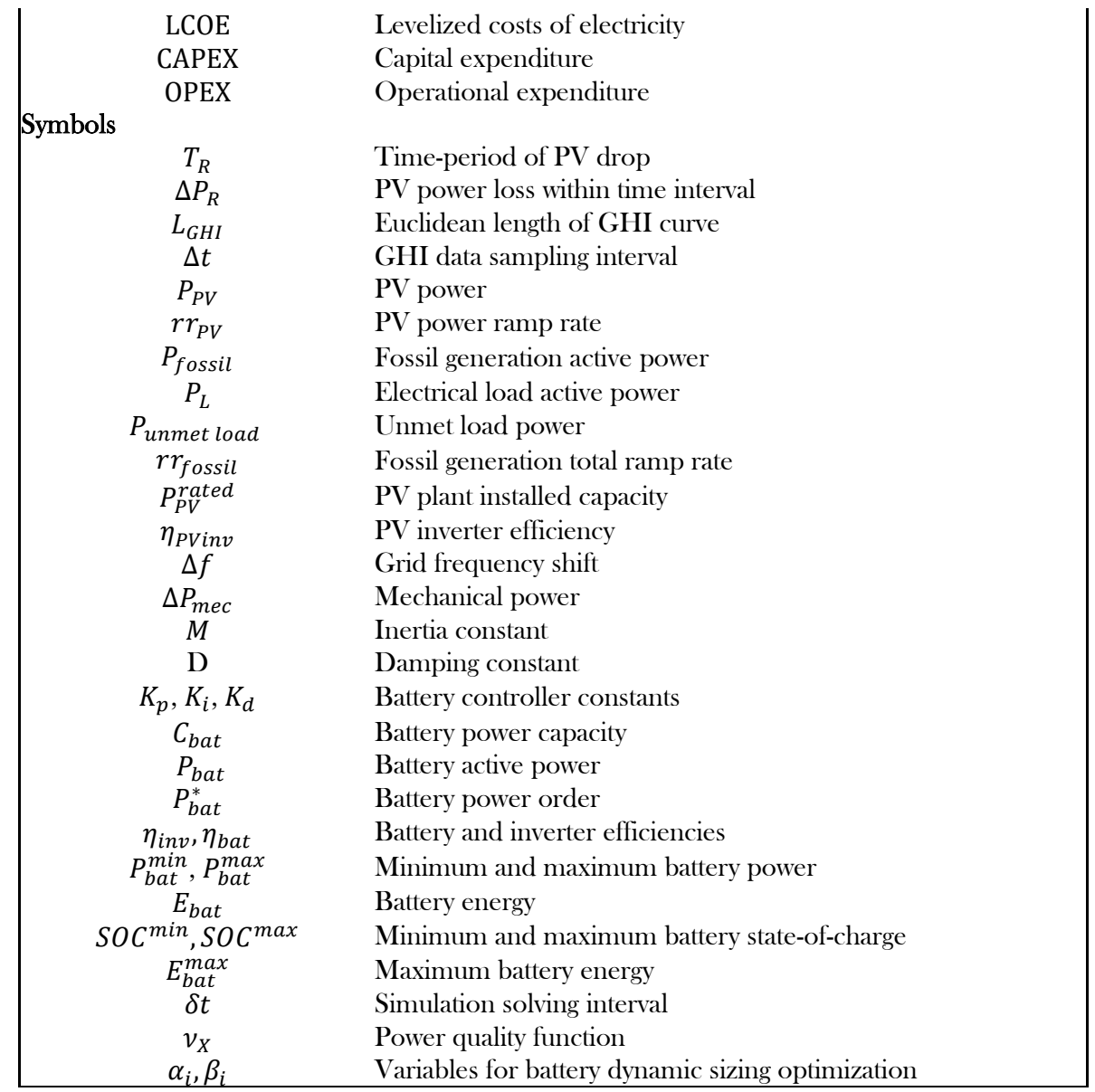

\section{Introduction}

Recent climate change trajectories and increasing political pressure over carbon legislation have made the establishment of an efficient low-carbon industry a priority. In its 2019 Outlook, the International Energy Agency (IEA) highlighted that powering facilities with low-carbon electricity constitutes one the main levers to achieve the industry's sustainable transition (1).

In developing countries with unreliable grids or large off-grid areas, industrial facilities must rely on onsite generation(2) and thus need to install their own renewable power plants to reduce their carbon emissions (3). In these applications, large-scale industrial microgrids will therefore play a key role.

So far, the need for affordable, reliable electricity has motivated the use of conventional fossil generation (gas-turbine or internal combustion engines) for electricity production. However, following the sharp drop in renewable electricity production costs, hybrid power plants featuring fossil generation and renewable resources are now drawing the attention of the scientific community since. Varying applications are found in the literature, from industrial microgrids (4) to water-treatment plants (5) and even future oil and gas platforms (6). Among the wide variety of renewable sources, solar PV is one of the most promising due to its fast development.

\subsection{Challenge of solar PV integration in off-grid industrial power plants}

The concept of industrial microgrids has not been extensively covered in the literature to date. The main sectors requiring such systems are the mining industry $(7)$, manufacturing industry $(8,9)$, water treatment (5) and upstream oil and gas (6). The main characteristics of such systems are: 
- High power ratings compared to conventional microgrid systems (from hundreds of $\mathrm{kW}$ to several hundreds of MW).

- Deterministic load profiles depending on the production schedule of the factory with a generally low level of variability.

- Strict reliability specifications regarding electricity supply for economic and safety reasons.

- Centralized ownership and operation for all production units.

Large scale integration of solar PV power with high short-term variability raises questions about the reliability and continuity of supply. As highlighted in (10), fossil-fuel generation lacks flexibility (long startup time, relatively low ramp-rate, etc.) and limits the renewable energy penetration rate. Additionally, integration of renewable resources contributes to reduce the mechanical inertia of the system which may lead to unstable grid and poor resilience to solar perturbation (11).

Storage systems are an effective way to compensate the lack of flexibility of fossil generation (12). Fast response technologies are the most suited to provide grid support, with an advantage for lithium-ion technologies considering recent projects and decreasing cost (13). However, storage systems significantly impact a plant's economic performance, which is why a deep understanding of solar variability is of paramount importance to support the development of industrial power plants.

\subsection{Assessment of solar variability and its impact on power system}

Accurate assessment of solar resources is a topic of growing importance for autonomous energy systems developers. Many software systems now use solar production profiles to determine optimal investments in components (14). In (15) for example, the battery power capacity is calculated using hourly on-site timeseries in order to compensate the lack of generation.

Since grid reliability is a key issue, a deeper analysis must be carried out (16). As frequency fluctuation occurs at short timescales due to instant power imbalances (17), solar short-term ramps have a strong impact on the system. Hence, defining solar variability scenarios is critical to determine the size of the battery system.

The production variability of photovoltaic (PV) systems is a complex phenomenon that is still being investigated by the scientific community to provide reliable metrics (18) and forecasts (19). Atmospheric conditions affect clouds' size, opacity and altitude, and also their horizontal and vertical movements. In addition, a site's characteristics, such as its orography, plays an important role in cloud dynamics (18). This makes the adaptation of variability indexes from one site to another almost impossible. On the other hand, high on-site resolution irradiance data are rarely available, making it necessary to conduct measurement campaigns whenever possible.

PV system size also plays a role in the variability since clouds may cast partial shade on the surface of large plants. In (20) it was shown that the power profile entirely follows the irradiance profile for time-ranges greater than 10 minutes. As reported in (21), short-term variability is affected by the size, shape and scattering of a plant. For plants of several megawatts, 1-s, 10-s, and 1-min ramps can be approximately $60 \%, 40 \%$, and $10 \%$ smaller, respectively, than those measured by a pyranometer.

Based on the work of (22), it is possible to simulate the effect of a plant's geometry on a single-sensor timeseries thanks to the Wavelet Variability Model (WVM). The risk of solar power ramp can then be evaluated with more accuracy.

Meanwhile, significant research has studied sizing technique and grid modelling with the aim of improving and optimizing the sizing of components (23). Battery sizing techniques range from pure energy compensation to maintain the power balance to a complex representation of the grid dynamics and frequency fluctuations (24). On the other hand, (25) highlighted that the relevance of performing highly detailed grid simulation can be challenging when the solar input scenarios have such high uncertainties. 
To the best of the authors' knowledge, no quantitative study has been performed to date to evaluate the role of accurate solar variability scenarios and storage sizing complexity in final battery capacity requirements. Additionally, the financial implications of such aspect remain unsettled in the literature.

To address this question, the paper is organized as follows. In section 2, we propose a methodology to identify a solar variability scenario from a high-resolution irradiance dataset. Then, we apply the WVM to simulate the smoothing effect of the PV power plant. Two metrics are proposed and combined to identify day-long and isolated scenarios. In section 3, we present two battery sizing methodologies with a theoretical background on power systems: power adequacy and dynamic modelling. These two methodologies are then applied in section 4 using a case study to quantify the role of the variability scenario and sizing method in the battery capacity requirement. Finally, we draw conclusions in section 5 .

\section{Addressing PV transients}

\subsection{Methodology and data}

As stated in the introduction, it is always preferable and more accurate to conduct an on-site measurement campaign. Yet, in the early stages of a project, the high costs and feasibility issues related to installing and operating a network of sensors prevent developers from obtaining reliable data on-site. A less costly approach is to use a worst-case referenced dataset. Thanks to the work carried out in (26), where solar variability zones were evaluated from a set of measurements of nine power plants, the area of Hawaii was found to be one of the most variable in the world in terms of solar irradiance. This is also confirmed by the results presented in (27). Taking a worst-case study perspective, in this paper we propose to use the data collected by NREL in Oahu (28) for variability analysis and battery sizing. Even though the meteorological behavior cannot be generalized to all regions in the world, we believe that such highly variable area like Hawaii can be an interesting benchmark for the scientific community.

Figure 1 shows the solar variability scenario identification procedure. After identifying a suitable dataset, the WVM is applied to the 1-second irradiance profile to simulate the smoothing effect of a $50 \mathrm{MW}$ solar power plant subject to a cloud speed of $20 \mathrm{~m} / \mathrm{sec}$.

Then, daily variability indexes are calculated to identify the most variable day. In this paper, we propose two indicators: the number of ramps detected using a ramp-detection algorithm (RDA) and the Variability Index (VI) derived from the work of J. Stein et al. (29).

Finally, we extract solar input scenarios for battery sizing from the most variable day. For the sake of clarity and simplicity, it is more convenient to consider solar variability events as typical solar drops (\% of PV power in a defined time interval) rather than using day-long timeseries. Thanks to the RDA, isolated ramp events are extracted from the day-long timeseries and are used as alternative variability scenarios. The uncertainties in the measurement of solar irradiance have been neglected since the information was not made available by data provider.

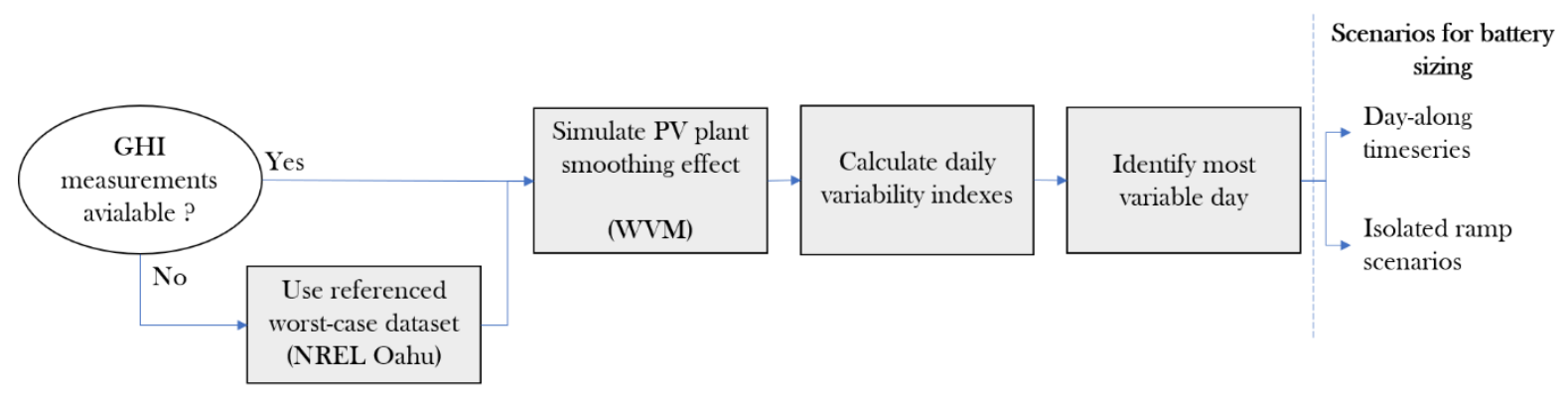

Figure 1 Scenario identification process 


\subsection{Quantifying solar variability}

\subsubsection{Ramp detection algorithm (RDA)}

Identifying solar ramps is a key step in solar variability analysis. Numerous methods can be implemented with varying levels of complexity. In (21), the solar profile 1 -second derivative is used to evaluate the ramp rate. This method can be extended to a larger fixed-time window, but this leads to neglect any change in irradiance within the time interval. In this case, such a method cannot be implemented because the timescale of the solar ramp is expected to vary between raw pyranometer data and WVM filtered data. In (30), a recognition method for irradiance transition was proposed based on moving averaged variations. Similarly, in this paper we propose to detect solar ramps thanks to a gradient-based adaptative sliding window.

The RDA detects each ramp with a higher gradient than the trigger value $A$ (in $\mathrm{W} \cdot \mathrm{m}^{-2} \cdot \mathrm{s}^{-1}$ ). The detected ramp, which is then labelled by its index $R$, has two attributes: $T_{R}$ the duration of the ramp and $\Delta P_{R}$ the power loss within the interval. The algorithm is provided in annex.

\subsubsection{Variability index (VI)}

In this study, we employ a variation of the variability index (VI) proposed by J. Stein et. al. in (29). The original index is calculated following Eq. 1 and can be interpreted as the ratio of the pyranometer global horizontal irradiance (GHI) measurement curve length over the clear-sky irradiance (CSI) curve length. The VI calculation proposed in this paper (Eq. 2) is very similar as it only replaces clear-sky irradiance by the hourly averaged GHI, with the aim of avoiding the use of clear-sky irradiance estimation models that may introduce additional bias.

$$
\begin{gathered}
V I=\frac{\sum_{t=t_{0}}^{t_{f}} \sqrt{\left(G H I_{t+1}-G H I_{t}\right)^{2}+\Delta t^{2}}}{\sum_{t=t_{0}}^{t_{f}} \sqrt{\left(C S I_{t+1}-C S I_{t}\right)^{2}+\Delta t^{2}}} \\
V I=\frac{L_{G H I}}{L_{\overline{G H I}}}
\end{gathered}
$$

$L_{G H I}$ and $L_{\overline{G H I}}$ are the euclidean dictance of the 1 sec GHI timeseries and hourly averaged GHI timeseries respectively.

$$
\begin{gathered}
L_{G H I}=\sum_{t=t_{0}}^{t_{f}} \sqrt{\left(G H I_{t+1}-G H I_{t}\right)^{2}+\Delta t^{2}} \\
L_{\overline{G H I}}=\sum_{h=h_{0}}^{h_{f}} \sqrt{\left(\overline{G H I_{h+1}}-\overline{G H I_{h}}\right)^{2}+3600^{2}}
\end{gathered}
$$

Figure 2 shows three irradiance profiles from the dataset with a VI value and the number of detected ramps. This shows that the number of ramps and VI in an RDA can give insight on the level of variability. The value of the VI are different from the indexes processed by Stein et. al. in (29), which range from 0 to 15. This is due to the fact that 1-min resolution data are used in (29), whereas 1-second data are used in this study, which obviously gives a longer GHI curve. 

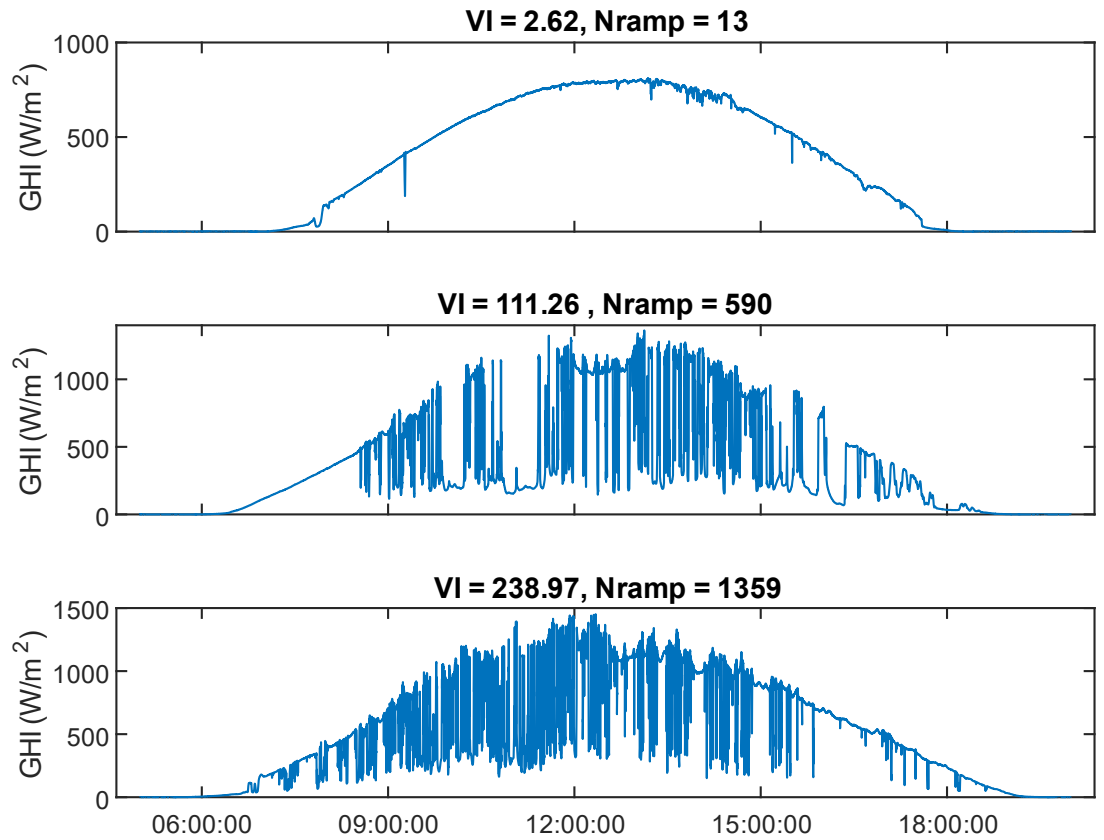

Figure 2 VI and Nramp index for 3 days in the Hawaii data-set

\subsection{Solar variability scenario identification}

We identify solar variability scenarios thanks to the maximum number of daily ramps detected by the RDA and the maximum VI over 1 year of data provided by NREL. The time-period goes from 2010-1001 to 2011-09-30 with measurements from 5am to 8pm and a 1-second sampling time. Ramps and VI are calculated for each day of the dataset, allowing the selection of worst-case scenarios. Figure 3 shows the ramp and VI distribution for each day. Table 1 shows the resulting metrics of RDA and VI for the most variable days identified. RDA and VI give the same worst-case day for the pyranometer data. However, the results reveal that the WVM has a clear impact on variability metrics, since the number of ramps dramatically drops from 1,359 to 257 for the 2011-07-08 timeseries. Additionally, it is worth mentioning that we do not obtain the same day-long scenario with the VI qualification after WVM-smoothing as compared to RDA qualification. 

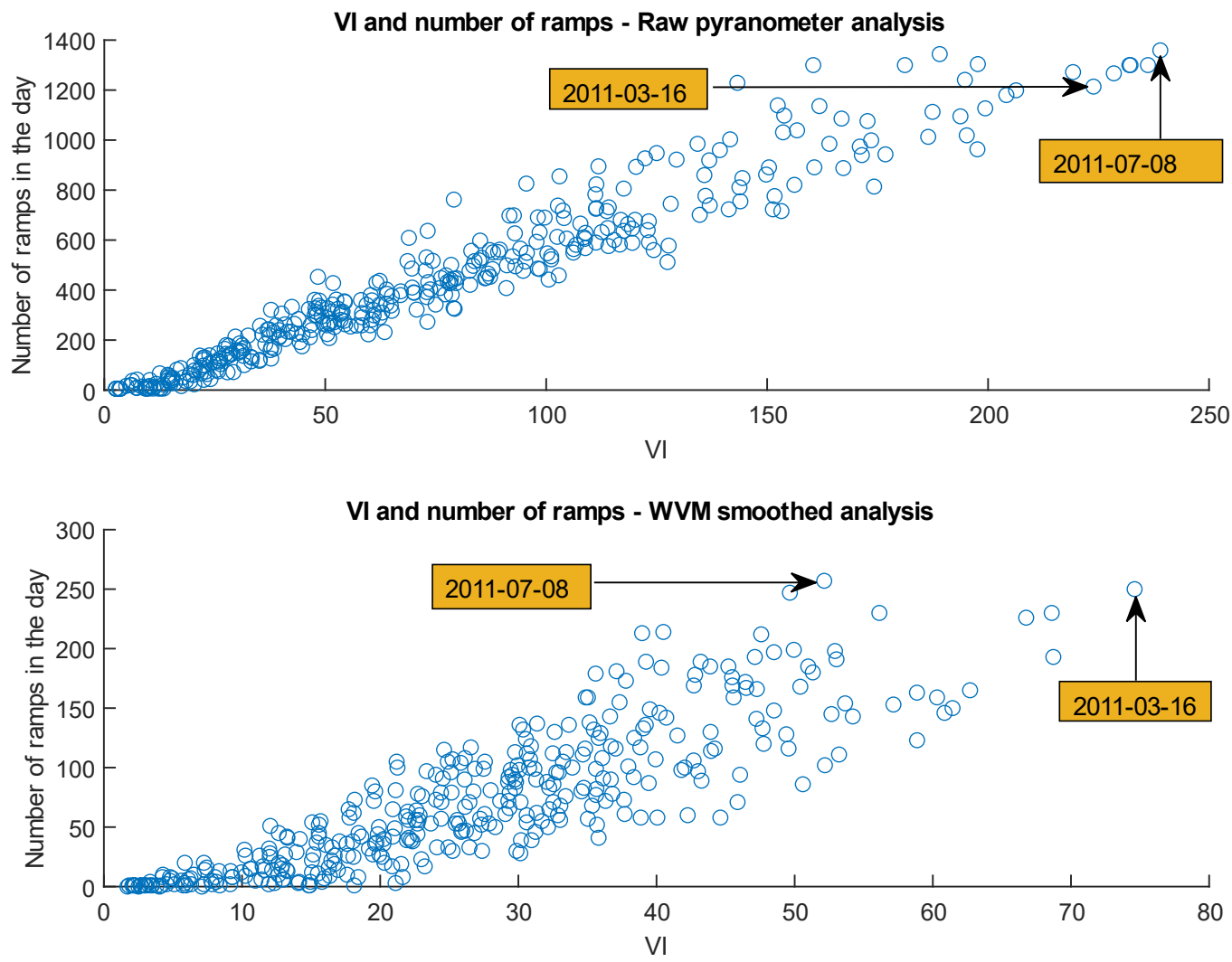

Figure 3 Scatter plot of detected ramp versus VI for all days between 2010-10-01 and 2011-09-30 using rawpyranometer timeseries (up) and WVM smoothed timeseries (down). The two selected scenarios are highlighted in the figure.

Day-long variability scenarios are identified from these results, henceforth referred to as $D^{\text {pyrano }}, D_{R D A}^{W v m}$ and $D_{V I}^{W v m}$ (see Table 1).

Table 1 Solar variability indexes of the worst cases for pyranometer data and WVM-smoothed data

\begin{tabular}{|c|c|c|}
\hline Qualification method & RDA & VI \\
\hline \multicolumn{3}{|l|}{ Pyranometer data } \\
\hline Scenario name & $D_{R D A}^{\text {pyrano }}$ & $D_{V I}^{\text {pyrano }}$ \\
\hline Date of worst case & \multicolumn{2}{|c|}{ 2011-07-08 } \\
\hline VI & \multicolumn{2}{|c|}{238.97} \\
\hline Number of ramps & \multicolumn{2}{|c|}{1359} \\
\hline \multicolumn{3}{|l|}{ WVM filtered data } \\
\hline Scenario name & $D_{R D A}^{W v m}$ & $D_{V I}^{W v m}$ \\
\hline Date of worst case & 2011-07-08 & $2011-03-16$ \\
\hline VI & 52.13 & 74.60 \\
\hline Number of ramps & 257 & 250 \\
\hline
\end{tabular}

\subsubsection{Isolated worst-case PV ramp scenarios}

For the sake of simplicity, it is more convenient to address solar variability as a single worst-case drop event characterized by the power loss $\Delta P_{R}$ and the duration of loss $T_{R}$ (in seconds). The evolution of the PV power is therefore expressed as:

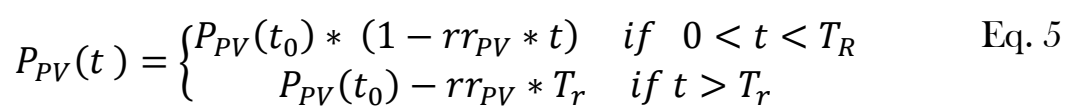


Where $r r_{P V}$ refers to the ramp rate given by:

$$
r r_{P V}=\frac{\Delta P_{R}}{T_{R}} \quad \text { Eq. } 6
$$

Thanks to the RDA, ramp characteristics can be easily extracted for each of the day-long worst-case scenarios previously defined. Figure 4 shows the highest number of detected ramps for scenarios $D_{R D A}^{\text {pyrano }}$ and $D_{R D A}^{w v m}$. Here again, the impact of the WVM clearly appears, since power drops are significantly reduced. We can see this looking for instance at the power drops at $T_{R}=15 \mathrm{sec}$, where the power drop varies from about 0.8 p.u for the pyranometer data to nearly 0.2 p.u for the WVM-smoothed data. However, for $T_{R}=30 \mathrm{~s}$, the power drop is very similar for both datasets. Yet it is not straightforward to choose one event from all of the pairs $\left(T_{R}, \Delta P_{R}\left(T_{R}\right)\right)$ since this will depend on the flexibility of conventional generation (see parts 3.1.1 and 3.1.2.1). This study therefore proposes to use the set of pairs $\left(T_{R}, \Delta P_{R}\left(T_{R}\right)\right)$ with $T_{R} \in[0,60]$ as isolated worst-case scenarios.

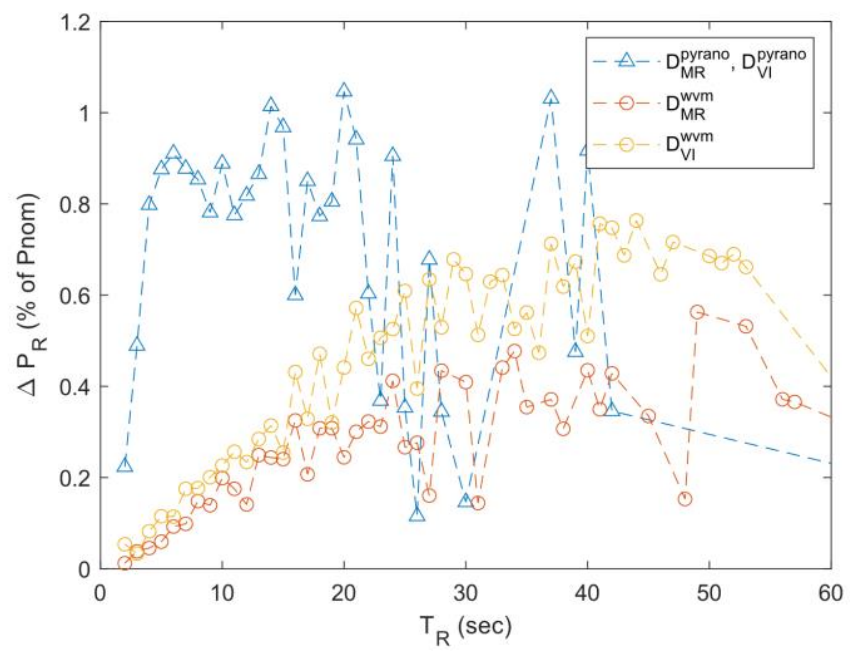

Figure 4 Highest $\Delta P_{R}$ for each $T_{R}$ among all detected ramps in each day-long scenario

In the next part of this study, isolated ramps extracted from $D^{\text {pyrano }}, D_{V I}^{w v m}$ and $D_{M R}^{w v m}$ are referred to as $I^{\text {pyrano }}, I_{V I}^{w v m}$ and $I_{M R}^{w v m}$

\subsubsection{Discussion on solar variability scenarios}

In this section, four day-long scenarios and two sets of isolated scenarios were identified. Thanks to the variability metrics (number of ramps and VI), it can be noted that the smoothing effect of the power plant's size is substantial. A ratio between 18 and 26 is observed between the VI of GHI timeseries and WVMsmoothed timeseries. Similarly, the PV power drop of the isolated scenario is reduced by up to $60 \%$ between the pyranometer and the WVM-smoothed timeseries, which remains consistent with (20) where a $40 \%$ variability reduction was estimated for the same timescale.

The worst-case, day-long and isolated scenarios are different depending on the metric used to extract the worst day (VI versus maximum ramps). Extracting a worst-case scenario using the maximum number of ramps leads to lower isolated drops for time periods above 30 seconds. This is expected to play a role in the battery power support requirement, which will be addressed in the next part. 
The isolated scenario extracted using the RDA shows ramp rates of between $2.25 \% / \mathrm{sec}$ and $1.25 \% / \mathrm{sec}$ with a maximum $72 \%$ drop in nominal power within 42 seconds for the set $I_{V I}^{W v m}$. This is a more comprehensive way of characterizing solar variability than considering the entire timeseries since it reduces it to a single drop event. However, the accuracy of the method needs to be proven by comparing the batteries obtained in both day-long and isolated scenarios.

The next section will evaluate the battery power requirements for each of the six identified scenarios while trying to determine the best way of addressing solar-PV variability.

\section{Battery power capacity sizing}

It has been shown in the previous section that the variability scenario can be significantly altered by more accurate modelling of the PV plant thanks to the WVM.

Similarly, a more detailed modelling of the power plant is expected to reduce the battery requirements for off-grid systems. This section will evaluate the battery capacity needs for two variability scenarios and compare the gain associated with an increase in model accuracy for the PV plant and the power system. This will be compared with the gain obtained by smoothing out the solar variability as well as the uncertainty introduced by the choice of variability scenarios.

\subsection{Methodologies for hybrid sizing}

\subsubsection{Power adequacy battery sizing}

A comprehensive, effective methodology for determining battery capacity consists in detecting the maximum power gap between the load and the generators. In (12), power adequacy battery sizing is used to compensate solar ramps when generators have insufficient ramping capacity. Eq. 7 and Eq. 8 show how the capacity is calculated while respecting the ramping constraint expressed by Eq. 9 .

$$
\begin{array}{cc}
P_{\text {unmet load }}(t)=P_{L}-P_{\text {fossil }}(t)-P_{P V}(t) & \text { Eq. } 7 \\
C_{\text {bat }}=\max _{t}\left(P_{\text {unmet load }}(t)\right) & \text { Eq. } 8 \\
P_{\text {fossil }}(t+1)-P_{\text {fossil }}(t)<r r_{\text {fossil }} & \text { Eq. } 9
\end{array}
$$

Where $P_{P V}$ is the PV power, $P_{\text {fossil }}$ is the power generated by fossil units, $P_{L}$ is the load demand and $P_{\text {unmet load }}$ is the amount of power that cannot be satisfied by the generating units. $C_{b a t}$ is the battery power capacity obtained by filling the power gap $P_{\text {unmet load }}$ during the PV power loss.

The PV power $P_{P V}$ is calculated from the PV plant's rated capacity and GHI value. A large number of advanced models exist to estimate PV plant performance based on optical and thermal simulation, such as presented in (31), but require a detailed description of the power plant (module types, electrical layout, etc.). In the context of variability analysis, the precise estimation of power absolute value is less important than the power dynamics. Hence, a linear model is used in this study as shown in Eq. 10 (a constant value of 0.97 is set for $\left.\eta_{P V i n v}\right)$.

$$
P_{P V}(t)=\frac{G H I}{1000 W / m^{2}} * P_{P V}^{r a t e d} * \eta_{P V i n v} \quad \text { Eq. } 10
$$

The main drawback of this methodology is the risk of capacity overestimation, as pointed out in $(12,32)$. The solution proposed by these papers was to allow ramp violation to prevent the sizing from being too 
conservative. However, this method does not allow for fully robust sizing, as it can endanger the quality of supply and even lead to electrical blackout for high renewable penetration rates.

\subsubsection{Dynamic electrical modelling}

\subsubsection{Application of power system theory to hybrid systems}

As stated in the literature review, an increasing level of complexity is observed in battery sizing studies. As a matter of fact, models with a low level of abstraction can evaluate power dynamics with more accuracy, which may have the effect of reducing the battery power requirements during PV transients. Instead of considering a perfect power equilibrium, dynamical studies aim to achieve power quality criteria at short timescales thanks to primary reserves (fossil generators and battery systems) whilst ensuring the continuity of load supply at longer timescales thanks to secondary and tertiary reserves (33). The role of energy storage systems in the frequency regulation paradigm has been extensively studied for large systems (34) as well as smaller isolated grids (35). In this study, only primary regulation is addressed.

For the sake of simplicity, we only address active power balance and frequency regulation here. Eq. 11 expresses the constraint on the frequency deviation and Eq. 12 formulates the relationship between frequency and power imbalance(17).

$$
\begin{array}{cc}
|\Delta f|<\Delta f_{\max } & \text { Eq. } 11 \\
\frac{d \Delta f}{d t}=\frac{\Delta P \operatorname{mec}-\left(\Delta P_{L}+D \Delta f\right)}{M} & \text { Eq. } 12
\end{array}
$$

When adding the solar PV system, fossil generator and battery system to Eq. 13 , this gives:

$$
\frac{d \Delta f}{d t}=\frac{\Delta P_{\text {fossil }}+\Delta P_{P V}+\Delta P_{\text {bat }}-\Delta P_{L}-D \Delta f}{M} \quad \text { Eq. } 13
$$

From Eq. 12 and Eq. 13 it can be deduced that taking mechanical inertia, load damping coefficient and frequency tolerance into account adds some flexibility to the system. The kinetic energy stored in the rotating masses is delivered prior to the primary reserve (fossil generation and battery), the load-damping coefficient reduces the electrical power in relation to the frequency drop, and finally the frequency tolerance allows small imbalances between the mechanical power and electrical power (see Figure 5 for 
graphical interpretation). This has the effect of reducing the primary reserve capacity requirement and therefore the battery power capacity.

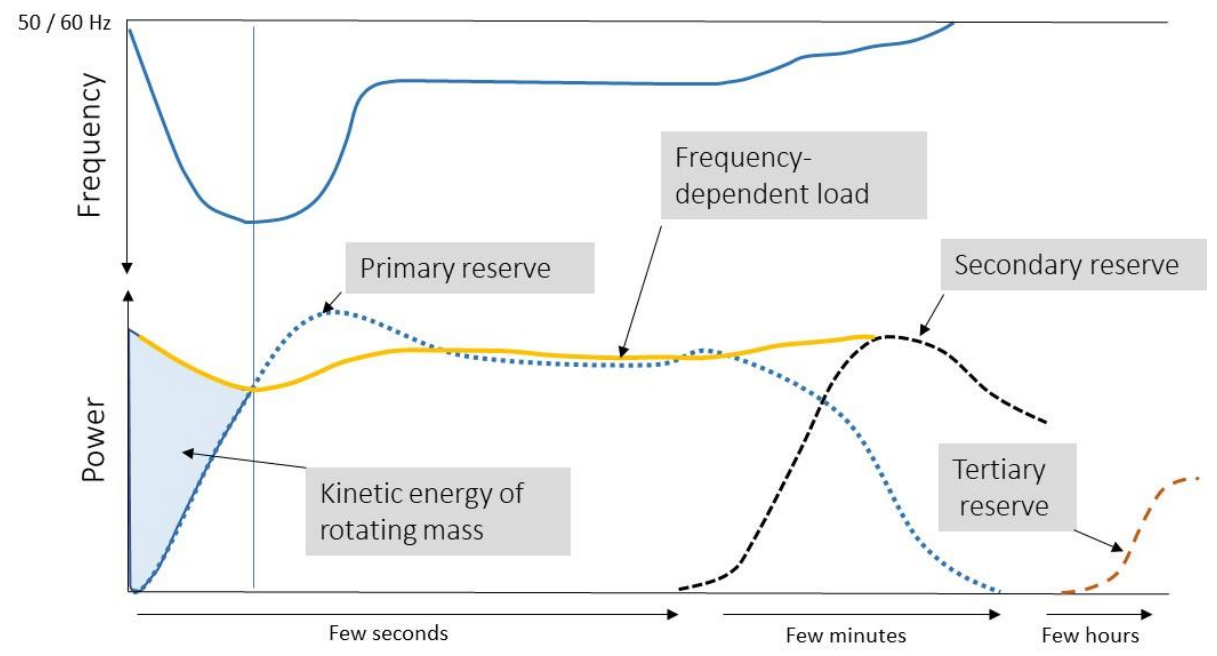

Figure 5 Evolution of frequency after a sudden load step (36).

\subsubsection{Battery sizing procedure}

The frequency deviation can be simulated to evaluate the minimal battery capacity required to satisfy the power quality criteria. This method is employed in several studies such as (37). Figure 6 shows the power system model. PV and load profiles are injected as time-series in the model.

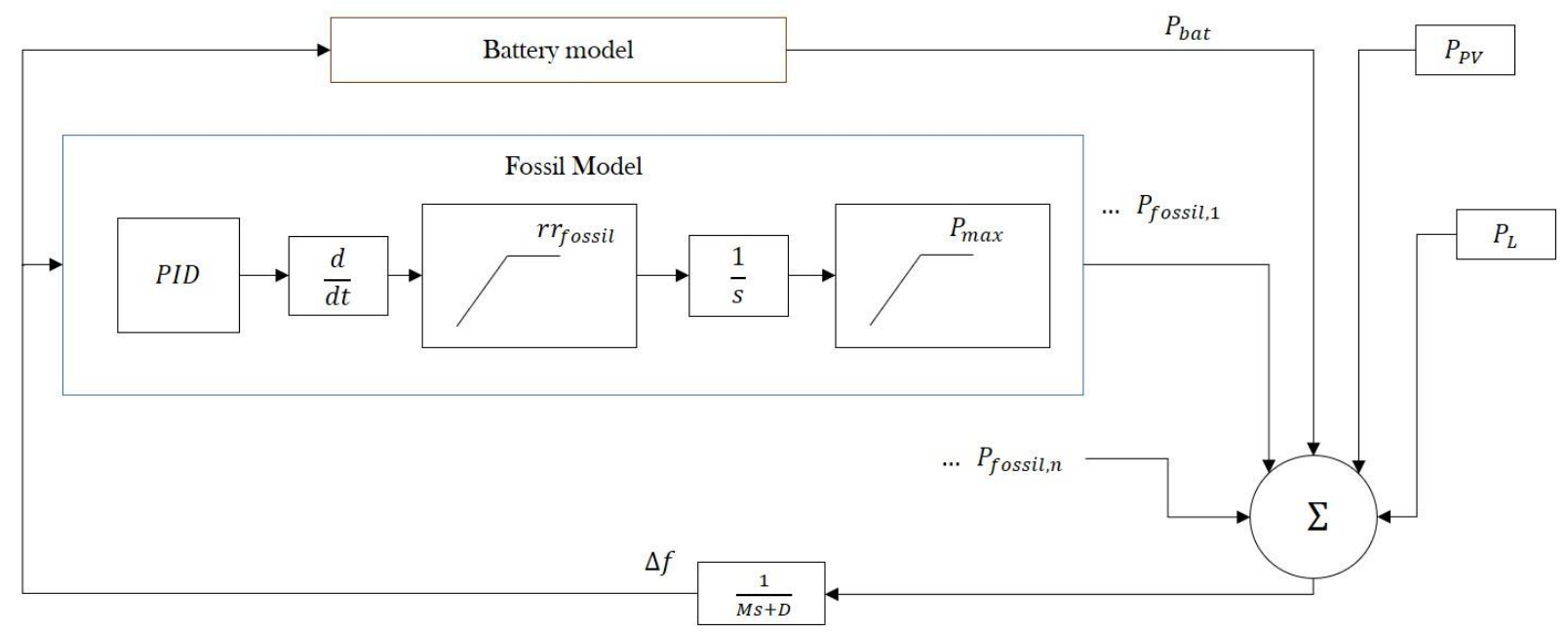

Figure 6 Power system and frequency regulation representation in the Laplacian domain

A proportional-integral derivative is used for the fossil generation contribution to frequency regulation and is expressed in Eq. 14. The control signal $P_{\text {fossil }}^{*}$ then passes through ramping and power capacity saturation blocks to obtain the power production $P_{\text {fossil }}$.

$$
P_{\text {fossil }}^{*}=K_{p} \Delta f+K_{i} \int \Delta f+K_{d} \frac{d \Delta f}{d t}
$$

An "energy-tank" model provides the storage dynamics as expressed in Eq. 17. Eq. 16 expresses the inverter charging and discharging efficiencies, whilst Eq. 18 and Eq. 19 provide boundaries for energy 
storage and power delivery. Values of 0.1 and 0.9 have been chosen for SOC boundaries similar to (38). The final power $P_{\text {bat }}$ delivered by the battery is integrated following Eq. 20 .

$$
\begin{aligned}
& P_{b a t}^{*}=K_{b a t} * \Delta f \\
& \eta_{S}=\frac{1}{\eta_{\text {inv }} \eta_{\text {bat }}} \text { if } P_{b a t}^{*}<0 \\
& \eta_{S}=\eta_{\text {inv }} \eta_{\text {bat }} \text { if } P_{b a t}^{*} \geq 0 \\
& E_{\text {bat }}(t+1)=E_{\text {bat }}(t)+\eta_{S} P_{b a t}^{*} \Delta t \\
& P_{b a t}^{\max } \leq P_{b a t}^{*} \leq P_{b a t}^{\min } \\
& E_{\text {bat }}^{\text {max }} S O C^{\text {min }} \leq E_{\text {bat }} \leq E_{\text {bat }}^{\max } S O C^{\max } \\
& P_{b a t}=\frac{\Delta E_{b a t}}{\delta t}
\end{aligned}
$$

Once the frequency timeseries has been simulated thanks to the dynamic model, an optimization method is necessary to obtain the minimal battery capacity. Several methods may be used with varying levels of complexity. For example, the authors in (39) implemented an analytic optimization with a fixed interval and a particle swarm optimization procedure to reduce computational time. In this paper, a bisection method is employed to evaluate the minimal battery requirements by running successive simulations and varying storage capacity. This method can reduce the number of iterations as compared to fixed-interval research. The searching interval is divided by 2 at each iteration until the final tolerance $\epsilon$ is reached. The bisection method aims at minimizing the battery capacity $P_{b a t}$ by evaluating the power quality function $v_{P_{b a t}}$ defined by Eq. 21. Since $v_{X}$ is expected to monotonically decrease, more complex optimization methods are not required to guarantee the convergence, although they may accelerate the solving time.

$$
v_{X}=\Delta f_{\max }-\min \left(\Delta f^{\operatorname{sim}} \mid C_{\text {bat }}=X\right) \quad \text { Eq. } 21
$$

Where $\Delta f^{\operatorname{sim}}$ is the frequency timeseries obtained by simulating the system with a battery power capacity $C_{b a t}$. The optimization procedure is shown in Annex. The searching interval is formed by $\left[\alpha_{i}, \beta_{i}\right]$, while $\alpha_{0}$ and $\beta_{0}$ are the lower and upper bounds for the optimization. The initial upper bound $\beta_{0}=C_{0}$ is given by the battery capacity calculated by the power adequacy method for the same scenario.

\subsection{Conclusion on sizing methodologies}

Power adequacy and dynamic sizing procedures have been described previously in this section. Thanks to the modelling of mechanical inertia and damping, as well as frequency shift tolerance, the battery capacity requirement is expected to be lower for dynamic sizing than for power adequacy. This makes it necessary to increase the level of complexity of sizing procedures and models. However, the scenarios identified in section 2 show various levels of perturbation. The wrong choice of variability scenario may eradicate the gains obtained by implementing a complex sizing strategy. In the next section, we employ the six scenarios identified as input for both sizing methodologies and compare the resulting battery power capacity. The overall process is shown in Figure 7. 


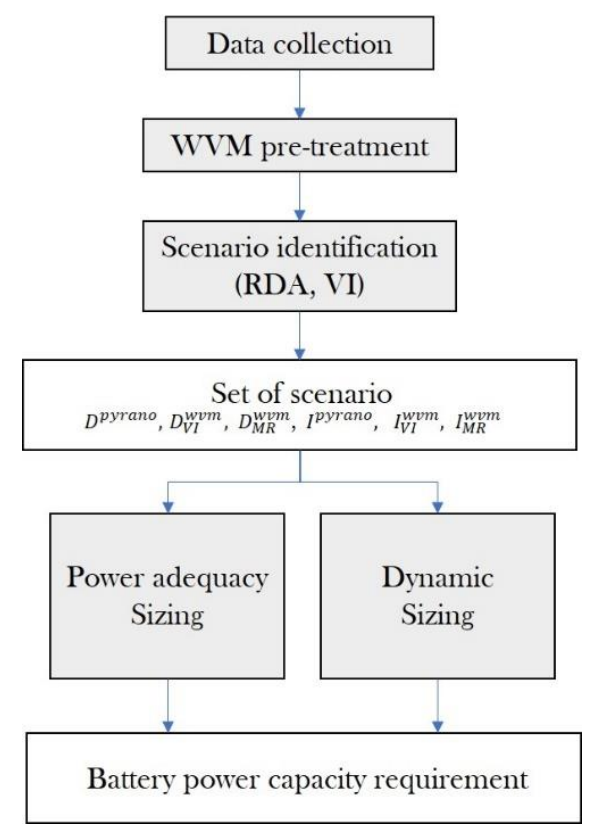

Figure 7 Summary of battery capacity requirement calculation from variability scenario identification to sizing methodology

\section{Application to a case study}

The proposed sizing methodologies were applied to the case of a hybrid power plant composed of four fossil generators of 50MW and a total electrical load of 100MW. As mentioned in section 1.1, the electrical demand of industrial power systems is less variable than conventional load demand in residential or tertiary microgrids. Moreover, due to the types of equipment generally installed (pumps, heaters, drivers), load variations are expected to occur at larger time scales than solar variations. Hence, the load profile is considered as constant in the case study. A generic lithium-ion battery is used with a $1 \mathrm{C}(1 \mathrm{kWh}-$ $1 \mathrm{~kW}$ ) power ratio. The plant dynamics was simulated using MATLAB/Simulink.

Table 2 List of parameters used for simulation

\begin{tabular}{cll}
\hline Parameters & Unit & Value \\
\hline Power plant parameter & & \\
\hline $\boldsymbol{r}_{\boldsymbol{f o s s i l}}$ & $\mathrm{MW} / \mathrm{sec}$ & 0.433 \\
\hline $\boldsymbol{P}_{\boldsymbol{P V}}^{\text {rated }}$ & $\mathrm{MW}$ & 50 \\
\hline $\boldsymbol{P}_{\boldsymbol{L}}$ & $\mathrm{MW}$ & 100 \\
\hline & & \\
\hline Fossil generator controller & & -0.2 \\
\hline $\boldsymbol{K}_{\boldsymbol{p}}$ & - & -0.05 \\
\hline $\boldsymbol{K}_{\boldsymbol{i}}$ & - & -0.2 \\
\hline $\boldsymbol{K}_{\boldsymbol{d}}$ & - & \\
\hline Power system constants & & 11.02 \\
\hline $\mathrm{M}$ & $\mathrm{Sec}$ & 0.02 \\
\hline $\mathrm{D}$ & - & 50 \\
\hline $\boldsymbol{f}_{\text {nom }}$ & $\mathrm{Hz}$ & 0.05 \\
\hline $\boldsymbol{\Delta} \boldsymbol{f}_{\boldsymbol{m a x}}$ & \% of $f_{\text {nom }}$ & \\
\hline
\end{tabular}

\section{Battery controller}




\begin{tabular}{lll}
\hline $\boldsymbol{K}_{\text {bat }}$ & - & 40 \\
\hline $\boldsymbol{\eta}_{\text {inv }}$ & - & 0.98 \\
\hline $\boldsymbol{\eta}_{\text {bat }}$ & - & 1 \\
\hline
\end{tabular}

\subsubsection{Power adequacy sizing}

The power adequacy sizing was applied to the scenarios presented in part 2.3.1. The set $I^{\text {pyrano }}$ gave a maximum power capacity requirement of $43.96 \mathrm{MW}$ which was found with the pair $\left(T_{R}=6 \mathrm{~s}, \Delta P_{R}=0.93\right.$ p.u). The $I_{M R}^{w v m}$ gave a power capacity requirement of $10.25 \mathrm{MW}$ against 21.34 for $I_{V I}^{w v m}$ (see Table 3). This results show that maximum battery capacity is not obtained with the same ramp duration, which justifies the use of a whole set of ramps. The power dispatch is plotted in Figure 8 for two isolated scenarios.

Table 3 Final battery capacity for isolated scenarios using power adequacy sizing

\begin{tabular}{lccc}
\hline Set & $\boldsymbol{I}^{\text {pyrano }}$ & $\boldsymbol{I}_{\boldsymbol{M R}}^{\boldsymbol{w v m}}$ & $\boldsymbol{I}_{\boldsymbol{V} \boldsymbol{I}}^{\boldsymbol{v v m}}$ \\
\hline $\begin{array}{l}\text { Max battery power } \\
\text { requirement (MW) }\end{array}$ & 43.96 & 10.25 & 21.34 \\
\hline Variability scenario & & & \\
\hline $\boldsymbol{T}_{\boldsymbol{R}}$ (s) & 6 & 24 & 29 \\
\hline $\boldsymbol{P}_{\boldsymbol{R}}$ (p.u of Pnom) & 0.93 & 0.41 & 0.67 \\
\hline
\end{tabular}

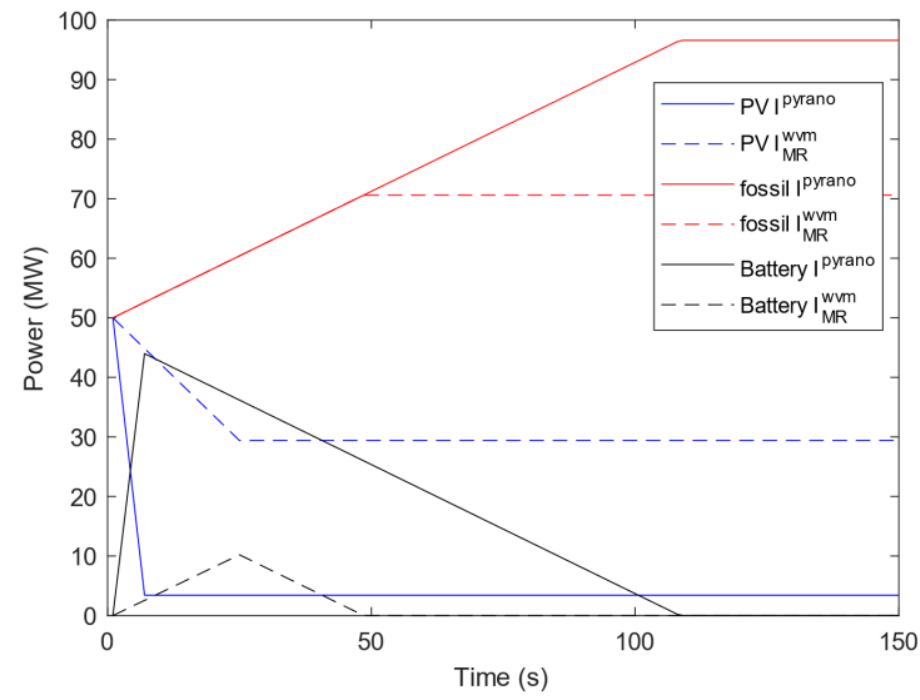

Figure 8 Ramp events with the highest battery requirements from sets $I^{\text {pyrano }}$ and $I_{M R}^{w v m}$ (method: power adequacy sizing).

Results for day-long scenarios $D^{\text {pyrano }}, D_{M R}^{w v m}$ and $D_{V I}^{w v m}$ give maximum battery power requirements of 44.7MW, 16.3MW and 25MW respectively.

\subsubsection{Dynamic model sizing}

To initialize the first interval for the bisection method, the value $C_{0}$ was set to the battery capacity found in 4.1.1 for the same scenario. Figure 9 shows the power dispatch obtained with both the power adequacy method and the dynamic simulation. The role of the frequency shift tolerance as a buffer clearly appears. The battery peak power is reduced from $21.34 \mathrm{MW}$ to $15.23 \mathrm{MW}$ with the dynamic model with a frequency maintained above -0.05 p.u. This confirms the ability of the dynamical model to refine battery requirements by taking the kinetic energy of rotors into account. 


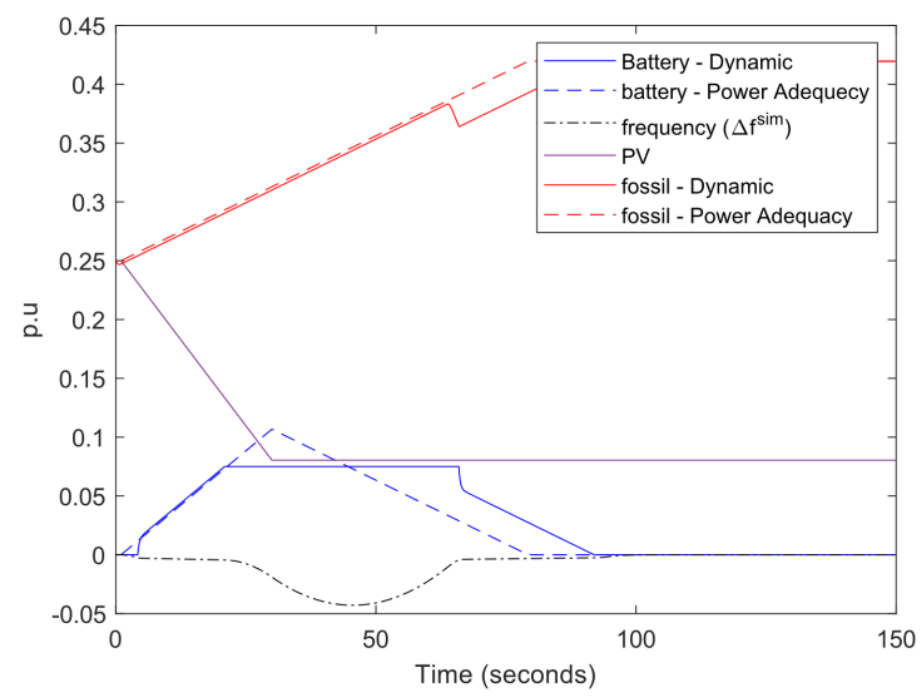

Figure 9 Power dispatch of scenario

$I_{V I}^{\text {Wvm }}$ with the power adequacy method (dashed lines) and dynamic modelling (continuous lines)

Similar results are observed for day-long scenarios as shown in Figure 10. The battery power resulting from the dynamic simulation is lower than for the power adequacy dispatch.
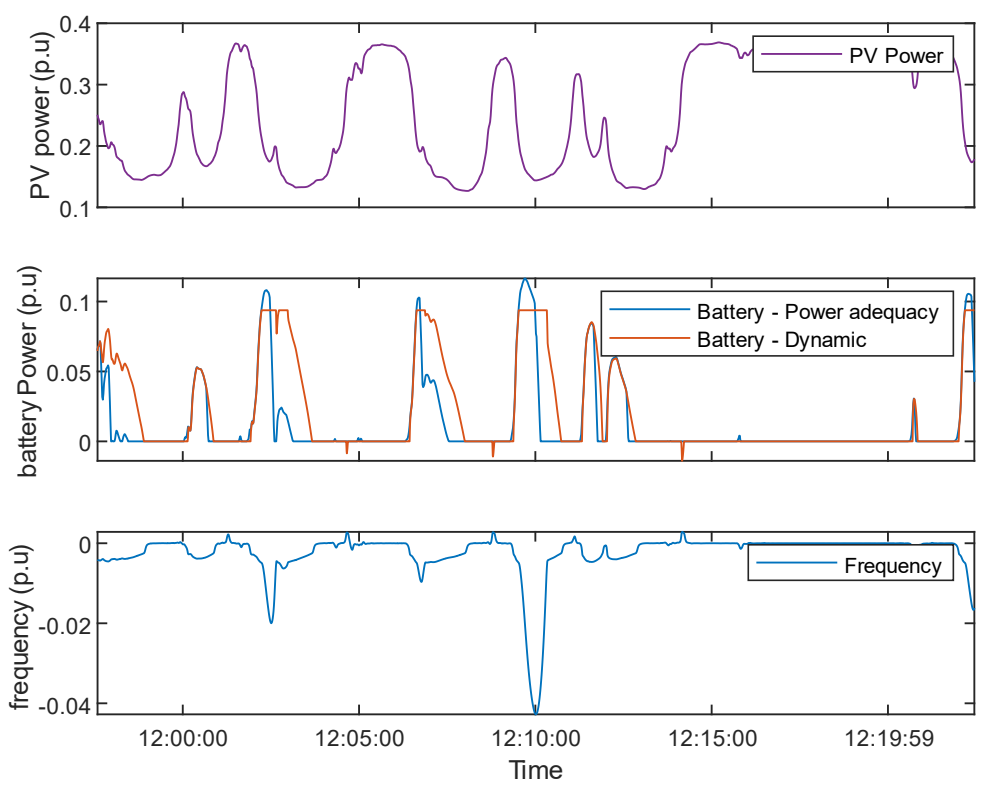

Figure 10 Power dispatch and frequency of scenario $D_{V I}^{w v m}$ obtained with power adequacy dispatch and dynamic simulation

The battery capacities obtained from coupling the optimization method and the dynamic simulation for all selected scenarios are presented in Table 4 . Figure 11 compares the final battery capacity requirements for all scenarios and both sizing methodologies.

For all scenarios, the battery capacities obtained by dynamic sizing are lower than the capacities obtained with power adequacy. Reductions of $8.4 \%, 25 \%$ and $9.8 \%$ are observed for day-long scenarios $D^{\text {pyrano }}, D_{M R}^{w v m}$ and $D_{V I}^{w v m}$ whereas reductions of $30 \%, 28 \%$ and $14 \%$ are observed for isolated scenarios 
$I^{\text {pyrano }}, I_{M R}^{w v m}$ and $I_{V I}^{w v m}$. This highlights the interest of improving the accuracy and complexity of power dispatch models. However, it should be noted that the gap between power adequacy and dynamic sizing may be sensitive to inertia constant, damping constant, frequency tolerance and battery control strategy. As an example, running the dynamic method for scenario $I_{V I}^{w v m}$ with an inertia constant of $5.51 \mathrm{~s}$ instead of $11.02 \mathrm{~s}$ gave a battery requirement of 19.42MW. The implementation of such models requires a high degree of confidence in power system parameters, which can be a challenge given that manufacturers' data are rarely made public.

This also comes at the cost of higher computation times, since several iterations are necessary to optimize the battery capacity: 19 minutes and 13 seconds are necessary to optimize the battery capacity for scenario $D^{\text {pyrano }}$ whereas 15 seconds are needed to run the power adequacy sizing for the same scenario (test run on a standard 4 core CPU with 8 Go of RAM ).

Unlike high model complexity, variability smoothing thanks to WVM has a much larger impact on battery capacity reduction. A capacity reduction of $63 \%$ is observed between day-long scenarios $D^{\text {pyrano }}$ and $D_{M R}^{w v m}$ and $43 \%$ between $D^{\text {pyrano }}$ and $D_{V I}^{w v m}$. As for isolated scenarios, capacity reductions of $76 \%$ between $I^{\text {pyrano }}$ and $I_{M R}^{w v m}$ and $51 \%$ between $I^{\text {pyrano }}$ and $I_{V I}^{w v m}$ are observed. The PV power plant smoothing effect can therefore be a better lever to reduce battery capacity requirements and avoid oversizing. In addition, assumptions made on cloud speed and location to obtain worst-case data tend to reduce the smoothing effect, which strengthens the results.

Additionally, Max ramp scenarios give a lower battery capacity than VI scenarios, regardless of the scenario type (isolated versus day-long) or modelling type (power adequacy vs dynamic modelling). Stein's Variability Index is therefore a better metric to qualify and extract the worst-case variability scenario after WVM smoothing.

Finally, differences between day-long scenarios and isolated scenarios should be carefully analyzed. The variation in battery capacity between all scenarios should be understood as a high level of uncertainty introduced by the choice of a variability scenario. The final battery requirement is generally lower for the isolated scenario, with high errors for $I_{M R}^{W V M}$. A difference of $18.5 \%$ is observed between $I_{V I}^{w v m}$ and $D_{V I}^{w v m}$. Despite the potential interest of combining VI and a max-ramp index to extract a worstcase isolated scenario ( $0.67 \%$ over 29 seconds in this study), the methodology needs to be improved to represent the overall variability.

Table 4 Final battery capacity for isolated and day-long scenarios using dynamic simulation

\begin{tabular}{lcccccc}
\hline & $\boldsymbol{D}^{\boldsymbol{p y r a n o}}$ & $\boldsymbol{D}_{\boldsymbol{M R}}^{\boldsymbol{w v m}}$ & $\boldsymbol{D}_{\boldsymbol{V I}}^{\boldsymbol{w v m}}$ & $\boldsymbol{I}^{\boldsymbol{p y r a n o}}$ & $\boldsymbol{I}_{\boldsymbol{M R}}^{\boldsymbol{w v m}}$ & $\boldsymbol{I}_{\boldsymbol{V I}}^{\boldsymbol{w v m}}$ \\
\hline $\begin{array}{l}\text { Minimum battery } \\
\text { capacity (MW) }\end{array}$ & 40.3 & 15.0 & 18.7 & 37.6 & 7.21 & 15.23 \\
\hline $\begin{array}{l}\text { Number of iterations } \\
\text { for optimization }\end{array}$ & 7 & 5 & 6 & 8 & 6 & 7 \\
\hline Minimum frequency & -0.048 & -0.011 & -0.46 & -0.043 & -0.038 & -0.043 \\
\hline
\end{tabular}




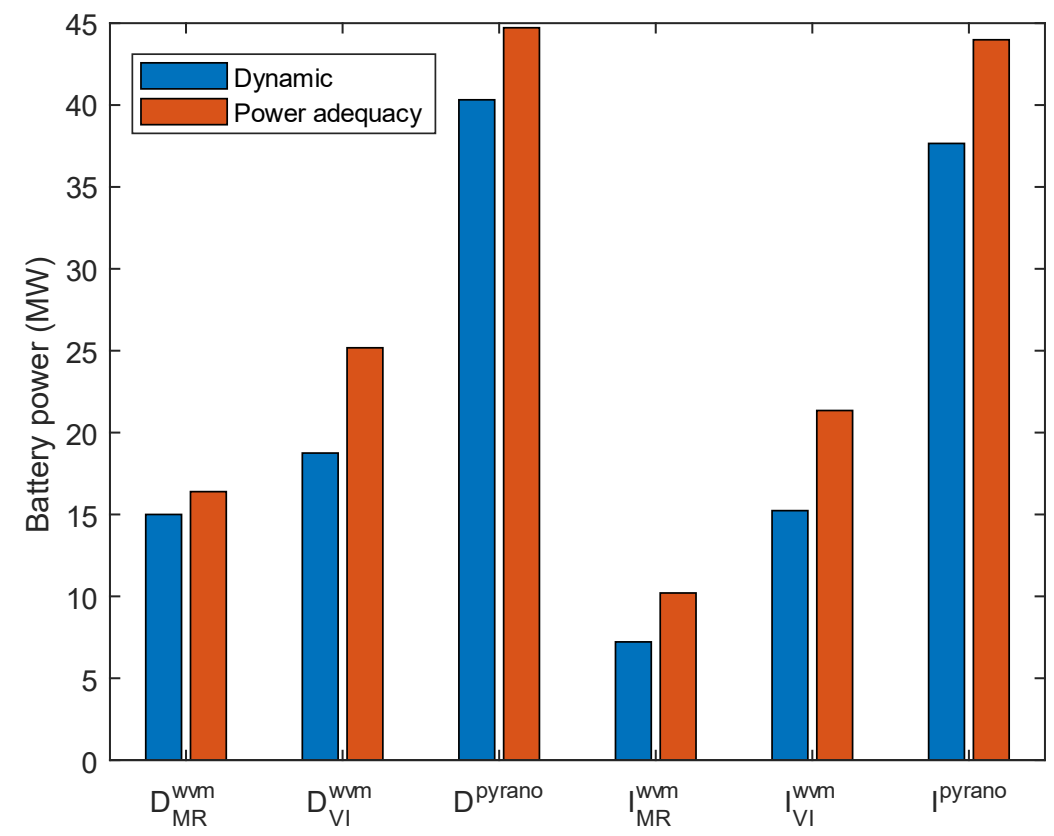

Figure 11 Summary of battery power requirements for all selected scenarios (blue: dynamic modelling, red: power adequacy sizing)

\subsubsection{Economic Analysis}

Bearing in mind the proposed microgrid configuration and the different battery solutions obtained after applying the different methodologies, we present a basic economic analysis of the solutions, considering two configurations:

- The first configuration (base case) is the fossil-based solution that provides a $100 \mathrm{MW}$ power supply during the 8,760 hours of the year.

- The second configuration considers the fossil-based power plant plus the $50 \mathrm{MWp}$ solar installation and a battery system with a capacity of $1 \mathrm{C}$, with a size corresponding to that presented in Table 4.

The approach is based in the analysis of the LCOE for both solutions, due to its acceptability in the evaluation and a comparison of power plant configurations in different contexts (40). In this paper, the following were considered: an inflation rate of $3 \%$, a return rate of $7 \%$, and a duration of 20 years for computing the LCOE.

Table 5 shows the different values that were considered in the economic analysis for computing the fixed and operational costs of the different components and fuel consumption. The information was extracted from available documents and databases providing fuel prices (41) and microgrid components costs (42). The chosen values allowed us to perform a relatively optimistic simulation in terms of battery prices, which decrease considerably every year, whereas an average value for the gas price was considered, bearing in mind the industrial contract that the plant operator might have for distribution.

Table 5 Selected prices for performing the economic analysis.

\begin{tabular}{lcc}
\hline & Interval & $\begin{array}{c}\text { Selected } \\
\text { Value }\end{array}$ \\
\hline Gas price $(\$ / \mathbf{k W h})$ & $0.00-0.125$ & 0.05 \\
\hline
\end{tabular}




\begin{tabular}{|c|c|c|}
\hline PV price $(\$ / k W p)^{*}$ & $0.50-1.10$ & 0.88 \\
\hline PV OPEX (\$ / MWp / yr) & $250-1000$ & 500 \\
\hline PV power degradation $(\% / \mathrm{yr})$ & $0.1-1.0$ & 0.5 \\
\hline Battery Price $(\$ / \mathrm{kWh}) * *$ & $350-600$ & 495 \\
\hline Battery inverter $(\$ / \mathrm{kW})^{* *}$ & $150-220$ & 200 \\
\hline Battery system OPEX (\% of CAPEX/yr) & $0.1-0.5$ & 0.5 \\
\hline
\end{tabular}

After performing the computations, the LCOE for the base solution was $\$ 145.5 / \mathrm{MWh}$, in which the fuel amounts to a cost of $\$ 100.31 \mathrm{M}$ for operations during the first year.

For the solutions that include the battery system, in which the added storage is considered only for covering renewable intermittence events, the fuel savings increase to $\$ 7.12 \mathrm{M}$ thanks to the theoretical production of 74,829.1 MWh from the solar installation.

Adding the battery system, the LCOE values obtained, condensed in Table 6 , vary from $\$ 119.06 / \mathrm{MWh}$ when using the battery obtained from the $I_{M R}^{V W M}$ and the dynamic sizing methodology (7.21 MWh), up to $\$ 123.08$ /MWh when using the $I^{\text {Pyrano }}$ proposal with power adequacy. This initial analysis, which needs to be supported by a more in-depth sensitivity analysis and an economic-oriented dispatch strategy that will be detailed in a further contribution, reduces the LCOE for the proposed conditions to $3.26 \%$.

Table 6 LCOE results for the different battery proposals per storage system methodology.

\begin{tabular}{lcccccc}
\hline Dynamic & $\boldsymbol{D}_{\boldsymbol{M R}}^{\boldsymbol{w v m}}$ & $\boldsymbol{D}_{\boldsymbol{M R}}^{\boldsymbol{w v m}}$ & $\boldsymbol{D}^{\text {pyrano }}$ & $\boldsymbol{I}_{\boldsymbol{M R}}^{\boldsymbol{w v m}}$ & $\boldsymbol{I}_{\boldsymbol{M R}}^{\boldsymbol{w v m}}$ & $\boldsymbol{I}^{\text {pyrano }}$ \\
\hline Battery Size & 15.23 & 18.7 & 40.3 & 7.21 & 15.0 & 37.6 \\
\hline LCOE (\$/MWh) & 120.00 & 120.29 & 122.61 & 119.05 & 119.89 & 122.23 \\
\hline Power Adequacy & $\boldsymbol{D}_{\boldsymbol{M R}}^{\boldsymbol{w v m}}$ & $\boldsymbol{D}_{\boldsymbol{M R}}^{\boldsymbol{w v m}}$ & $\boldsymbol{D}^{\boldsymbol{p y r a n o}}$ & $\boldsymbol{I}_{\boldsymbol{M R}}^{\boldsymbol{w v m}}$ & $\boldsymbol{I}_{\boldsymbol{M R}}^{\boldsymbol{w v m}}$ & $\boldsymbol{I}^{\boldsymbol{p y r a n o}}$ \\
\hline Battery Size (MWh) & 16.4 & 25.2 & 44.72 & 10.2 & 21.34 & 44.0 \\
\hline LCOE (\$/MWh) & 120.04 & 120.98 & 123.08 & 119.37 & 120.57 & 123.01 \\
\hline
\end{tabular}

\section{Conclusion}

This paper looks at the problem of battery sizing for off-grid hybrid systems. It includes a comparison of the roles of solar variability scenarios and sizing methodology complexity in battery requirement calculations.

A yearly Global-Horizontal Irradiance (GHI) dataset showing conservative variability characteristics was identified to extract variability scenarios. Two metrics were used to address the daily solar variability: the maximum number of ramps detected by a ramp detection algorithm, and the variability index proposed by Stein et al. Six scenarios were then proposed: raw pyranometer GHI versus wavelet-variability-model (WVM) smoothed irradiance, day-long versus isolated ramp scenarios, and maximum ramp versus variability index.

The impact of these variability scenarios on battery sizing was then studied using two different sizing methodologies with varying levels of complexity. The simple method (power adequacy) consists in ensuring the power equilibrium between power sources and loads using the battery system as an adjustment variable. The complex method takes power system dynamics into account and consists in identifying the minimum battery capacity that satisfies power quality constraints.

The results show that applying WVM smoothing in order to take a plant's geographic smoothing into account has more potential to reduce battery capacity oversizing than increasing the sizing method complexity (51\% against 25\%). 
This shows that the power plant smoothing effect and the proper variability scenario extracted are crucial for estimating battery capacity and must not be neglected during hybrid power plant sizing. Neglecting the power plant smoothing effect may lead to a significant over-estimation of the battery capacity, and therefore higher electricity costs. On the other hand, a proper scenario identification method avoids battery underestimation and therefore prevents the degradation of power quality and grid reliability. This can be illustrated by basic economic analysis of the hybrid solutions in which the battery system overestimation will increase the levelized costs of electricity of the system, thus representing additional operational costs.

Lastly, the combination of VI and a ramp-detection algorithm to identify a worst-case isolated ramp scenario led to an error of $18.5 \%$ as compared to the day-long simulation. One perspective to continue with this work is to improve the isolated scenario generation to obtain a better match with worst-case daylong scenarios and simplify battery sizing procedures.

\section{Annex}

\subsection{Annex 1 Ramp detection algorithm}

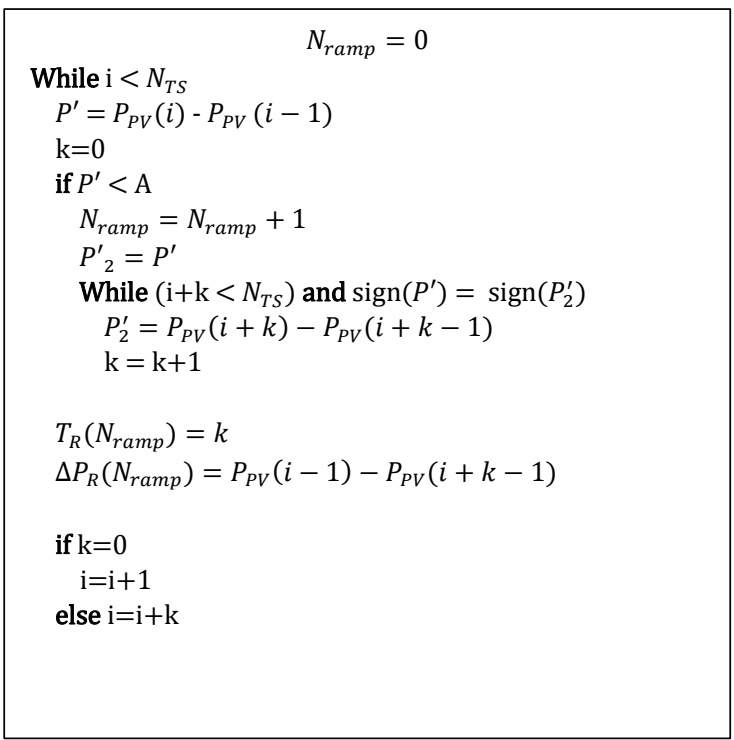

Figure 12 Ramp-detection algorithm 


\subsection{Annex 2 Battery sizing optimization procedure}

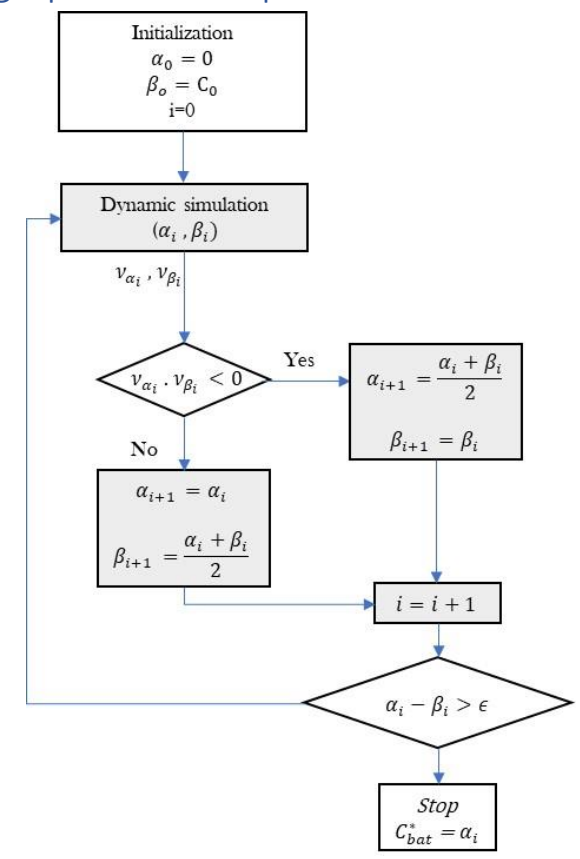

Figure 13 Battery optimization procedure

\section{References}

1. IEA. Tracking Industry [Internet]. Paris: IEA; 2019 May [cited 2019 Apr 23]. (Tracking report). Available from: https://www.iea.org/reports/tracking-industry

2. Alby P, Dethier J-J, Straub S. Firms Operating under Electricity Constraints in Developing Countries. The World Bank Economic Review. 2013;27(1):109-32.

3. Rissman J, Bataille C, Masanet E, Aden N, Morrow WR, Zhou N, et al. Technologies and policies to decarbonize global industry: Review and assessment of mitigation drivers through 2070. Applied Energy. 2020 May 15;266:114848.

4. Hamedani Golshan ME, Masoum MAS, Derakhshandeh SY. Profit-based unit commitment with security constraints and fair allocation of cost saving in industrial microgrids. IET Science, Measurement \& Technology. 2013 Nov 1;7(6):315-25.

5. Soshinskaya M, Crijns-Graus WHJ, van der Meer J, Guerrero JM. Application of a microgrid with renewables for a water treatment plant. Applied Energy. 2014 Dec 1;134:20-34.

6. Riboldi L, Nord L. Offshore Power Plants Integrating a Wind Farm: Design Optimisation and Techno-Economic Assessment Based on Surrogate Modelling. Processes. 2018 Dec 4;6(12):249.

7. ARENA. Weipa solar farm - Australian Renewable Energy Agency (ARENA) [Internet]. Australian Renewable Energy Agency. [cited 2019 Apr 23]. Available from: https://arena.gov.au/projects/weipa-solar-farm/ 
8. Nosratabadi SM, Hooshmand R-A, Gholipour E, Rahimi S. Modeling and simulation of long term stochastic assessment in industrial microgrids proficiency considering renewable resources and load growth. Simulation Modelling Practice and Theory. 2017 Jun;75:77-95.

9. Subramanyam V, Jin T, Novoa C. Sizing a renewable microgrid for flow shop manufacturing using climate analytics. Journal of Cleaner Production. 2020 Apr 10;252:119829.

10. Kubik ML, Coker PJ, Barlow JF. Increasing thermal plant flexibility in a high renewables power system. Applied Energy. 2015 Sep;154:102-11.

11. Banjar-Nahor KM, Garbuio L, Debusschere V, Hadjsaid N, Pham T-T-H, Sinisuka N. Study on Renewable Penetration Limits in a Typical Indonesian Islanded Microgrid Considering the Impact of Variable Renewables Integration and the Empowering Flexibility on Grid Stability. In: 2018 IEEE PES Innovative Smart Grid Technologies Conference Europe (ISGT-Europe) [Internet]. Sarajevo, Bosnia and Herzegovina: IEEE; 2018 [cited 2019 Mar 7]. p. 1-6. Available from: https://ieeexplore.ieee.org/document/8571673/

12. Makibar A, Narvarte L, Lorenzo E. On the relation between battery size and PV power ramp rate limitation. Solar Energy. 2017 Jan 15;142:182-93.

13. Wilson M. Lazard's Levelized Cost of Storage Analysis-Version 6.0. 2020;40.

14. Lian J, Zhang Y, Ma C, Yang Y, Chaima E. A review on recent sizing methodologies of hybrid renewable energy systems. Energy Conversion and Management. 2019 Nov 1;199:112027.

15. HOMER Energy. HOMER - Hybrid Renewable and Distributed Generation System Design Software [Internet]. [cited 2019 Mar 19]. Available from: https://www.homerenergy.com/

16. Mashayekh S, Stadler M, Cardoso G, Heleno M, Madathil SC, Nagarajan H, et al. SecurityConstrained Design of Isolated Multi-Energy Microgrids. IEEE Trans Power Syst. 2018 May;33(3):2452-62.

17. Kundur PS. Power system stability and control. Indian edition. Balu NJ, Lauby MG, editors. Mc Graw Hill Education (India) Private Limited; 1994. 1176 p. (The EPRI power system engineering series).

18. Lauret $P$, Perez R, Mazorra Aguiar L, Tapachès $E$, Diagne HM, David M. Characterization of the intraday variability regime of solar irradiation of climatically distinct locations. Solar Energy. 2016 Feb 1;125:99-110.

19. Lappalainen K, Wang GC, Kleissl J. Estimation of the largest expected photovoltaic power ramp rates. Applied Energy. 2020 Nov 15;278:115636.

20. Mills A, Ahlstrom M, Brower M, Ellis A, George R, Hoff T, et al. Dark Shadows. IEEE Power and Energy Magazine. 2011 May;9(3):33-41.

21. Cormode D, Cronin AD, Richardson W, Lorenzo AT, Brooks AE, DellaGiustina DN. Comparing ramp rates from large and small PV systems, and selection of batteries for ramp rate control. In: 2013 IEEE 39th Photovoltaic Specialists Conference (PVSC) [Internet]. Tampa, FL, USA: IEEE; 2013 [cited 2019 Jul 18]. p. 1805-10. Available from: http://ieeexplore.ieee.org/document/6744493/

22. Lave M, Kleissl J, Stein JS. A Wavelet-Based Variability Model (WVM) for Solar PV Power Plants. IEEE Transactions on Sustainable Energy. 2013 Apr;4(2):501-9. 
23. Hannan MA, Faisal M, Jern Ker P, Begum RA, Dong ZY, Zhang C. Review of optimal methods and algorithms for sizing energy storage systems to achieve decarbonization in microgrid applications. Renewable and Sustainable Energy Reviews. 2020 Oct 1;131:110022.

24. Anoune K, Bouya M, Astito A, Abdellah AB. Sizing methods and optimization techniques for PVwind based hybrid renewable energy system: A review. Renewable and Sustainable Energy Reviews. 2018 Oct;93:652-73.

25. Jayashree S, Malarvizhi K. Methodologies for Optimal Sizing of Battery Energy Storage in Microgrids: A Comprehensive Review. In: 2020 International Conference on Computer Communication and Informatics (ICCCI). 2020. p. 1-5.

26. Lave M. Solar variability zones: Satellite-derived zones that represent high-frequency ground variability. Solar Energy. 2017;10.

27. Lave M, Reno MJ, Broderick RJ. Characterizing local high-frequency solar variability and its impact to distribution studies. Solar Energy. 2015 Aug 1;118:327-37.

28. Sengupta M, Andreas A. Oahu Solar Measurement Grid (1-Year Archive): 1-Second Solar Irradiance; Oahu, Hawaii (Data) [Internet]. 2010 [cited 2019 Mar 19]. Available from: http://www.osti.gov/servlets/purl/1052451/

29. Stein J, Hansen C, Reno MJ. The variability index: A new and novel metric for quantifying irradiance and PV output variability. Sandia National Laboratories; 2012.

30. Lappalainen $\mathrm{K}$, Valkealahti S. Recognition and modelling of irradiance transitions caused by moving clouds. Solar Energy. 2015 Feb 1;112:55-67.

31. F. Holmgren W, W. Hansen C, A. Mikofski M. pvlib python: a python package for modeling solar energy systems. JOSS. 2018 Sep 7;3(29):884.

32. Jahromi AA, Majzoobi A, Khodaei A, Bahramirad S, Zhang L, Paaso A, et al. Battery Energy Storage Requirements for Mitigating PV Output Fluctuations. In: 2018 IEEE PES Innovative Smart Grid Technologies Conference Europe (ISGT-Europe). 2018. p. 1-5.

33. Farrokhabadi M, Cañizares CA, Simpson-Porco JW, Nasr E, Fan L, Mendoza-Araya PA, et al. Microgrid Stability Definitions, Analysis, and Examples. IEEE Transactions on Power Systems. 2020 Jan;35(1):13-29.

34. Greenwood DM, Lim KY, Patsios C, Lyons PF, Lim YS, Taylor PC. Frequency response services designed for energy storage. Applied Energy. 2017 Oct 1;203:115-27.

35. El-Bidairi KS, Nguyen HD, Mahmoud TS, Jayasinghe SDG, Guerrero JM. Optimal sizing of Battery Energy Storage Systems for dynamic frequency control in an islanded microgrid: A case study of Flinders Island, Australia. Energy. 2020 Mar 15;195:117059.

36. Fraisse J-L, Karsenti L. Raccordement de la production décentralisée aux réseaux de distribution - Conditions d'intégration. 2014;41.

37. Alves E, Sanchez S, Brandao D, Tedeschi E. Smart Load Management with Energy Storage for Power Quality Enhancement in Wind-Powered Oil and Gas Applications. Energies. 2019 Aug 2;12(15):2985. 
38. Cominesi SR, Farina M, Giulioni L, Picasso B, Scattolini R. Two-layer predictive control of a microgrid including stochastic energy sources. In: 2015 American Control Conference (ACC). 2015. p. 918-23.

39. Kerdphol T, Qudaih Y, Mitani Y. Battery energy storage system size optimization in microgrid using particle swarm optimization. In: IEEE PES Innovative Smart Grid Technologies, Europe. 2014. p. 1-6.

40. Pawel I. The Cost of Storage - How to Calculate the Levelized Cost of Stored Energy (LCOE) and Applications to Renewable Energy Generation. Energy Procedia. 2014 Jan 1;46:68-77.

41. Electricity prices around the world [Internet]. GlobalPetrolPrices.com. [cited 2021 Jun 30]. Available from: https://www.globalpetrolprices.com/electricity_prices/

42. IRENA. Utility-scale batteries - Innovation Landscape Brief [Internet]. 2019 p. 24. Available from: https://www.irena.org/-/media/Files/IRENA/Agency/Publication/2019/Sep/IRENA_Utilityscale-batteries_2019.pdf 